\title{
Vivências de Jongo com crianças na escola: educação das relações étnico-raciais
}

\author{
Jongo experiences with children at school: education of ethnic-racial relations
}

Vivencias de Jongo con niños en la escuela: educación de las relaciones étnico-raciales

\author{
VÍVian PARreira da Silva ${ }^{1}$; AIDA Victória GarCia MonTrone ${ }^{2}$ \\ UNIVERSIDADE FEDERAL de São CARLOS, UFSCAR, São CARLOS-SP, BRASIL
}

\begin{abstract}
RESUMO
O ensaio apresenta experiências fundamentadas em vivências de Jongo na escola como caminho possível para práticas educativas antirracistas. Este trabalho é fruto de pesquisa de doutorado e o objetivo é apresentar como os processos educativos decorrentes de vivências de Jongo realizadas em uma escola da cidade de São Carlos com crianças de seis e sete anos podem contribuir para a implementação da lei 10.639/03. As reflexões aqui apresentadas buscaram trazer nossos anseios e apontar os desafios e caminhos que percorremos na construção do diálogo entre universidade, escolas e as comunidades. Podemos destacar que os processos educativos vivenciados em diálogo com os saberes jongueiros, são ferramentas de luta ancestral para esperançarmos uma educação que promova vida, diversidade, afeto e coragem.
\end{abstract}

Palavras-chave: Processos Educativos. Jongo. Educação das Relações Étnico-Raciais. Esperançar.

\begin{abstract}
The essay presents experiences based on experiences of Jongo at school as a possible way for anti-racist educational practices. This work is the result of doctoral research and the objective is to present how the educational processes resulting from experiences of Jongo carried out in a school in the city of São Carlos with children aged six and seven can contribute to the implementation of law 10.639/03. The reflections presented here sought to bring our desires and point out the challenges and paths we have taken in building the dialogue between universities, schools and communities. We can highlight that the educational processes experienced in dialogue with the jongueiro knowledge, are tools of ancestral struggle to hope for an education that promotes life, diversity, affection and courage.
\end{abstract}

Keywords: Educative Processes. Jongo. Education of Ethnic-Racial Relations. To Hope.

\section{RESUMEN}

El ensayo presenta experiências fundamentadas en vivencias de Jongo en la escuela como un camino posible para prácticas educativas antiracistas. Este trabajo és fruto de la investigación de doctorado y el objetivo és presentar como los procesos educativos que surgen de vivencias de Jongo realizadas en una escuela de la ciudad de São Carlos con niños de seis y siete anos pueden contribuir para la implementación de la ley 10.639/03. Las reflexiones presentadas buscan traer nuestros anhelos y apuntar los desafios y caminos que hemos tomado en la construcción del diálogo entre universidad, escuelas y comunidades. Podemos destacar que los procesos educativos vivenciados en diálogo con los conocimientos jongueros, son herramientas de lucha ancestral con la esperanza de una educacación que promueba vida, diversidad, afecto y coraje.

Palabras clave: Procesos Educativos. Jongo. Educación de las Relaciones Étnico-Raciales. Esperanza.

\footnotetext{
${ }^{1}$ Doutora em Educação pela UFSCar. E-mail: vivian@teia.org.br. ORCID: https://orcid.org/0000-0003-03996168 .

${ }^{2}$ Professora Associada da UFSCar. E-mail: montroneufscar@gmail.com. ORCID: http://orcid.org/0000-00021954-4679.
} 
ABRINDO CAMINHOS, RE-INICIANDO A RODA...

Neste momento, nosso desejo é partilhar as nossas experiências em educação das relações étnico-raciais, particularmente a partir de nossa pesquisa ${ }^{3}$ realizada, no ano de 2018, junto a crianças de sete e oito anos de uma escola pública da cidade de São Carlos, que teve como objetivo compreender como os processos educativos decorrentes de uma intervenção de Jongo contribuem para viabilizar a implementação da lei 10.639/03 (BRASIL, 2003).

Desde o ano de 2003 a Lei 10.639/03, posteriormente alterada pela lei 11.645/08 (BRASIL, 2008) prevê a obrigatoriedade do ensino das culturas africanas, afrobrasileiras e indígenas em todos os ambientes de ensino públicos e particulares do país.

Políticas de ações afirmativas, para implementar tais leis, vêm sendo realizadas em diferentes locais e com diversas metodologias de trabalho, porém sabemos que há, ainda hoje, um abismo entre o que a lei prevê e a sua concretização, ou seja, ainda é muito baixo o número de escolas que conseguiram alcançar êxito nos trabalhos de efetivação de tais políticas públicas.

Dito isso, vale a pena dizer também que, no Brasil as lutas antirracistas, os trabalhos pelo reconhecimento e valorização das histórias africanas, afro-brasileiras e indígenas vêm sendo feitos com grandes esforços, tendo enfrentamentos grandiosos por parte de grupos e comunidades que lutam contra a estrutura branca e elitista que ainda vigora em nossa sociedade.

A escravidão fincou e propagou no Brasil o racismo, que vigora e opera cotidianamente em diferentes espaços. Diante desta lógica, temos aprendido em diálogo e ações com grupos diversos que as lutas educam para a vida, pois os saberes se constroem em ação, em convivência, em partilha de experiências. Falar, portanto, sobre o esperançar a partir desta perspectiva é falar de luta, luta em diferentes lugares, contextos e com diferentes pessoas que, com projetos de mundo que visam à humanização, esperançam viver com amor e dignidade.

Deste modo, nossas pesquisas são tempo e espaço para sentirmos e percebermos o mundo de outros jeitos. Nos encontramos em constante aprendizado no que se refere ao ato de pesquisar, por isso estamos em ação-reflexão-ação, em busca de exercitar o que aqui apresentamos enquanto bases teóricas, como nos orienta Freire (1996).

Os saberes fundados nas culturas da diáspora africana configuram-se como saberes de comunidade enraizados e projetados na ancestralidade, na memória, na corporeidade, na tradição, ou seja, saberes que contribuem para a manutenção da tradição e garantem sua transmissão de geração a geração. São, portanto, saberes que fortalecem a esperança para sermos mais, para exercitarmos o inédito viável, são saberes que promovem vida, contrariando as lógicas de morte impostas pelo sistema colonial.

Com efeito, a produção do conhecimento, a obediência à norma da ancestralidade (respeita os idosos), a vivência do princípio político por excelência: garantir o bem de todos e de cada um (trabalhar para o progresso da família e da comunidade), e a integração com o meio ambiente são pilares fundamentais da educação africana e afrodescendente todo esforço social africano está voltado para o bem estar da comunidade (OLIVEIRA, 2007, p. 275).

\footnotetext{
3 Este ensaio é parte da pesquisa de doutorado intitulada "Jongo na escola: contribuições para e na educação das relações étnico-raciais" (SILVA, 2020) e do trabalho apresentado no Sexto Seminário da Linha de pesquisa Pesquisas em Práticas Sociais e Processos Educativos realizado em novembro de 2019, na Universidade Federal de São Carlos.
} 
Todo este esforço para o bem estar da comunidade muitas vezes não encontra espaço na escola. A educação escolar promove muitas vezes a competição e não fortalece a construção de laços de comunidade para que, juntos, todos possam ser mais. Então, os nossos esforços se concentram em promover metodologias de trabalho que se alicercem nos pilares fundamentais de uma educação humanizadora que considera e reconhece as diversas existências.

\section{APRENDER NAS E COM AS RODAS...}

Aprender e ensinar nas rodas de Jongo, nos terreiros, nas congadas, nas capoeiras se configura como oportunidade para vivenciarmos uma educação fundada no esperançar, no comprometimento com a vida e com a ancestralidade.

Acreditamos que a característica democrática e criadora da escola pode ser retomada quando nos disponibilizamos em caminhar junto com ela na busca por diferentes perspectivas que nos permitam repensar as nossas histórias e papéis.

\footnotetext{
Notamos, como Paulo Freire, que enquanto centro de poder, o Norte se acostumou a perfilar o Sul. O norte 'norteia' o Sul; assim, tradicionalmente, nortear, no sentido de fornecer ou imprimir orientação no campo científico, tem significado adotar teorias, enfoques, compreensões, intervenções e soluções geradas a partir de problemáticas, ideologias e entendimentos próprios da Europa, primeiro, e da região do Atlântico Norte, depois, regiões estas que impuseram e mantiveram a colonialidade das outras regiões. Mais do que isso, reforçaram a ideia de superioridade/inferioridade tomando a si próprios como referência, modelo padrão ou "normalidade". Exemplo disso são as representações ou projeções cartográficas de nossos continentes; seja na projeção de Mercator (em 1569), seja na de Peters (em 1973), tomados como mapas padrão, ambos situam a Europa no meio do mundo (ARAÚJOOLIVERA, 2014, p. 48-49).
}

Quando praticamos uma educação à luz de sabedorias africanas e ameríndias, estamos aprendendo e ensinando desde o nosso lugar, estamos exercitando ser nós mesmas a partir de outras epistemes. Com esta prática estamos, de algum modo, lutando contra a assimilação e evocando outras existências e novos jeitos de ver o mundo a partir de uma educação que exercita o esperançar.

Em acordo com Freire (2008), esperançar requer ir à luta, construir, ir atrás, viver e buscar a coerência dos discursos que proferimos enquanto educadoras progressistas. Esperançar não é esperar, aguardar, conformar, pelo contrário é construir o caminho para a transformação. O Jongo existe, resiste, transforma, ensina, é o esperançar em sua concretude.

Considerando o Jongo como sendo a vida de quem o vive, de quem o reinventa, de quem o dança, de quem o repassa, ele é então, uma prática que carrega histórias, vidas e saberes construídos na diáspora por homens e mulheres que "[...] se reconstruíram a partir de seus cacos" (SIMAS; RUFINO, 2018, p.13) ao serem submetidos ao trauma da escravidão. De acordo com Mestre Gil,

O Jongo é o código de postura. É uma dança profana de roda e de umbigada criada para divertimento em horas de lazer. Mas dominada pelos antigos, possui no seu arranjo um caráter rígido quanto ao respeito aos mais velhos, além de um sistema de representações retidas e repetidas nas mirongas (base dos pontos e de seu intrincado arranjo). Admitimos como poetas-feiticeiros, 
os mais velhos dotados da capacidade de liderança, desafiam-se nas rodas de Jongo para disputar os conteúdos entendidos como de sabedoria. Ou para sintonizar as tensões sofridas no cotidiano, entendidas pela comunidade como pressões do processo de exclusão. Grito de alerta disfarçado na singeleza do verso a cantoria passa aos ouvintes como divertimento, quando seu sentido é resistente (SILVA, 2007, p. 33).

$\mathrm{Na}$ singeleza e na resistência dos cantos, no acolhimento das rodas o Jongo vai resistindo, ensinando e proporcionando pertencimento, fortalecimento e existência, se mantém vivo nos corpos e memórias de quem canta, dança e brinca na roda. As comunidades jongueiras vivem o esperançar em práxis de vida, vivenciam o verbo, o fazem sentido da vida, pois desde a colonização resistimos e esperançamos a vida em sua totalidade, pois o que está aí nos causa desesperança.

Em certo modo, vivemos atualmente uma dialética do esperançar e da desesperança, pois sabemos que o que está aí não serve a um projeto de mundo que busca a diversidade como possibilidade real de transformação. Neste caso, nosso esperançar se ancora em ações que visam deslegitimar uma única visão de mundo que homogeniza, que aniquila e assimila vidas, histórias e culturas.

Deste modo, nos posicionamos ao lado de quem historicamente luta para existir, considerando todas as dimensões da pessoa humana, considerando os saberes da diáspora forjados nos corpos e memórias de homens e mulheres aqui escravizados. Podemos dizer que para uma educação das relações raciais, que positive as culturas de matriz africana é necessário mudança de postura, uma reorganização ética e estética, um chamado a outras visões, outros mundos, outras mentalidades outras belezas, outras ciências, outras maneiras de ser e estar em diálogo com o mundo, é preciso esperançar.

Nossa esperança que não espera, busca em ação com parceiros e parceiras agir em espaços, como nas escolas, para que possamos protagonizar outras histórias, outras versões que valorizam as lutas, as maneiras de aprender e ensinar baseadas em outras lógicas e filosofias como as africanas e indígenas.

Trata-se de descolonizar o saber, de desconstruir significados e compreensões homogenizantes, tidos como universais, para nos abrirmos a novos jeitos de ser, de viver, de pensar, de organizar e significar a vida dos povos que foram colonizados e sofreram e sofrem a tentativa de europeizá-los ou de se parecer com os europeus. Fazendo nossas as palavras de Silva, esclarecemos que "é preciso entender que não se trata de simples rejeição a pensamentos de mudança de pontos de apoio para compreender fenômenos [...] mas de necessidade de nova mentalidade" (ARAÚJO-OLIVERA, 2014, p. 90).

A partir das leis 10.639/03 e 11.645/08, hoje é possível identificar práticas e ações que buscam positivar as identidades e culturas africanas em diferentes espaços. No caso da presente pesquisa, em diálogo com a escola, buscamos combater com nossas escritas e com nossas ações o silêncio que reforça a opressão, o desconhecimento, a negação de direitos, o silêncio que legitima e naturaliza o racismo. Em diálogo com autores e autoras, com as crianças e com a professora, vivenciamos experiências que envolveram rodas de conversa, canto, dança, criação coletiva, histórias, tudo alicerçado no Jongo, prática cultural de matriz africana. Dialogamos na e com a roda. Acreditamos na potência das tecnologias ancestrais, dos saberes do povo jongueiro como caminho e jeitos de ser e estar no mundo, em luta, vivendo o esperançar.

A partir da análise dos registros das conversas e convivências na escola com as crianças e com a professora, o esperançar e a positivação das culturas africanas e afrobrasileiras se mostraram potentes. 


\section{NOSSAS RODAS COM AS CRIANÇAS...}

Quando iniciamos nossas vivências, a turma acolheu a prática em seu cotidiano, o Jongo ganhou lugar no convívio da turma, a brincadeira, a disponibilidade em conhecer e acolher o novo nos ensinou também que para transformar é preciso olhar, ouvir, ver e vivenciar o que outras perspectivas e modos de vida nos propõem.

A receptividade das crianças para o Jongo é, sem dúvidas, caminho favorável para viver, reconhecer, aprender e compartilhar o conhecimento. Denzin (2018) em sua pesquisa realizada também por meio de uma intervenção com africanidades junto a crianças mostrou que reconhecer para conhecer é condição importante, para que possamos nos livrar de nossos preconceitos e nos abrirmos à diversidade.

Dialogando com Paulo Freire (2008), sobre a Esperança como Pedagogia, sabemos que uma das tarefas da educação popular progressista, é procurar, por meio da compreensão crítica de como se dão os conflitos sociais, ajudar o processo no qual a fraqueza dos oprimidos se vai tornando força capaz de transformar a força dos opressores em fraqueza. Esta é uma esperança que nos move.

Conhecer e reconhecer as diferentes histórias de luta que fundam este país e consequentemente conhecer e valorizar seus protagonistas, como as mulheres e homens negros que lutaram e lutam para que o Jongo e tantas outras práticas culturais ainda existam, é caminho para transformar a fraqueza imposta aos oprimidos em força que move e em esperança que transforma.

Deste modo, a oportunidade de termos uma formação que nos mostre os tambores, os cantos, as rodas, os berimbaus, os jogos africanos, a literatura africana, que reconheça os reis e rainhas conga, uma formação que nos aponte tudo isso como forma de aprender, viver e compartilhar conhecimento é uma formação que vai contra uma educação de assimilação e de dominação, é uma forma de esperança em poder exercer a transformação que buscamos.

Conhecer nos possibilita respeitar outras maneiras de construir e compartilhar conhecimento, e nos move contra o epistemicídio (SANTOS; MENESES, 2010), praticado no passado por meio da escravidão, que ainda vigora alicerçado no racismo que gera o ódio ao povo e às culturas negras e indígenas. $\mathrm{O}$ desconhecimento ou a pouca aproximação com as culturas indígenas e africanas nos rende uma educação preconceituosa baseada em informações distorcidas.

Dialogamos então diretamente com Freire (1996, p. 96), que nos diz que a “[...] educação não transforma o mundo. Educação muda pessoas. Pessoas transformam o mundo", deste modo a luta antirracista e a construção de projetos de educação que reconheçam as histórias e culturas africanas e afro-brasileiras passam essencialmente pelos posicionamentos de homens e mulheres em diálogo no e com o mundo em suas ações.

Escolhas e posicionamentos, portanto, se tornam fundamentais para $\mathrm{o}$ comprometimento com a implementação da Lei 10.639/03. A história do Brasil, escrita nos livros didáticos, sobretudo naqueles produzidos antes da existência da Lei supracitada, nos conta um lado, uma versão da história a partir de uma perspectiva racial branca que se proclama superior. Nossos estudos existem para que não neguemos mais a importância e a relevância da vida de inúmeros povos marginalizados na construção da história do país. Nomear outros heróis e heroínas faz parte da luta contra a epistemologia dominante - ela se cristaliza na história oficial ao priorizar histórias brancas e promover o apagamento das vidas e culturas dos povos negros e indígenas. A 
história oficial se configura, portanto, como ferramenta opressora que viabiliza a manutenção da lógica dominadora.

Desta forma, conhecer, receber e compartilhar conhecimento sobre os povos negros significa também reconhecer a presença do racismo e as suas consequências.

[...] em conversa com Quero-quero ${ }^{4}$, enquanto acontecia a roda das crianças ele me disse que o Jongo ensinou muitas coisas pra ele, a ser amigo a respeitar, ver as histórias dos negros, ensinar os brancos a respeitarem eu perguntei se brancos e negros podem fazer Jongo juntos ele disse: sim podem fazer juntos, mas quem são os mestres sou eu e Beija-flor (Quero-quero e Beija-flor são duas crianças negras de pele retinta). Depois de responder ele pegou o tambor e foi tocar na roda (Pesquisadora, Diário de Campo, 10 dez. 2018).

Esta fala de Quero-quero se deu após a presença de Mestre Lumumba ${ }^{5}$ na escola. Importante problematizarmos nossas referências de costumes, de educação, de beleza, afinal todos os dias olhamos, ouvimos, comemos, vestimos, escrevemos, vivemos fixados e alimentados pelo padrão branco e eurocêntrico. Quero-quero diz que todo mundo pode fazer Jongo junto, mas os mestres serão ele e Beija-flor que assim como ele tem a pele retinta. Ele compreendeu que ele também pode ser o professor, o mestre. Não que as crianças brancas também não possam se reconhecer e ser as referências, os mestres e mestras da brincadeira, mas geralmente elas - e os brancos adultos - ocupam com frequência os lugares de protagonismo. Nas conversas com Vanessa sobre as possibilidades de dialogar sobre o racimo dentro da escola ela afirma:

[...] é importante mudar a lógica eu não mudo a lógica só no projeto só com a aula de capoeira eu mudo a lógica nisso [...] por exemplo, eu vejo uma família negra constantemente? A campanha do dia dos pais do boticário colocou uma família negra e o povo surtou por quê? [...] quantas famílias negras existem aí? Porque surtaram? Porque estamos mudando a lógica estamos tirando este lugar de privilégio e que privilégio é este que está subalternizando outras pessoas? Que está desumanizando outras pessoas quando a família negra não é considerada? (Primeira conversa com a Professora participante da pesquisa, Diário de Campo, 10 out. 2018).

Mudar a lógica implica também em problematizar as referências. Deste modo, os processos educativos gerados em vivências e práticas que priorizam histórias de pessoas e comunidades negras nos possibilitam propor outro jeito de racionalidade, outro jeito de contar, de conhecer as histórias, outros jeitos de construir conhecimentos na coletividade. As vivências promovem também o reconhecimento e o combate ao racismo engendrado nos espaços e currículos. As vivências e convivências nas rodas de Jongo dentro e fora do espaço escolar são força motriz para que possamos dialogar as experiências, é uma ação dentre tantas outras que buscam entrelaçamento de vozes para que possamos esperançar histórias mais cheias de vida.

\footnotetext{
${ }^{4}$ Em acordo com a aprovação no Comitê de Ética em Pesquisa em Seres Humanos da UFSCar, parecer número 2.752.225, todos os nomes das crianças foram substituídos por nomes de pássaros para garantir a segurança e anonimato das colaboradoras e colaboradores da pesquisa.

5 Mestre Lumumba é o nome escolhido por Benedito Luiz Amauro, filho do orixá Ogum, poeta, compositor, músico, militante cultural há mais de 40 anos, diretor artístico, Oni'Ylu (construtor de tambores) e Alabe. Em 1987, com a Yalorixá Nadya Santana fundam a Comunidade Cultural Religiosa de Matriz Africana Ilê Asè Omò Ayé, que reúne pessoas de diferentes cidades do estado de São Paulo que compartilham a fé nos orixás, os princípios da vida comunitária e o gosto pela cultura e arte afrobrasileiras.
} 
Com isto, a esperança é uma atitude ética da experiência formativa da pessoa que só pode acontecer como possibilidade de uma educação que propicie o desenvolvimento de uma autonomia, por meio da participação democrática na sociedade. Com relação a essa riqueza popular e de que tanto podemos aprender, me lembro de sugestões que andei fazendo a vários educadores e educadoras em contato amiudado com trabalhadores urbanos e rurais, no sentido de irem registrando estórias, retalhos de conversas, frases, expressões, que pudessem proporcionar análises semânticas, sintáticas, prosódicas do seu discurso. Em certo momento de um esforço como este, seria possível propor a diferentes grupos de trabalhadores, como se fossem codificações, as estórias ou as frases, ou os retalhos de discursos, já estudados com, sobretudo, a colaboração de sociolinguistas, e testar a compreensão que das frases das estórias, tinham tido os educadores, submetendo-a aos trabalhadores. Seria um exercício de aproximação das duas sintaxes - a dominante e a popular (FREIRE, 2008, p. 72).

Acreditamos, juntamente com Paulo Freire (2008), que o comprometimento de educadoras e educadores com um modelo de educação progressista requer uma formação baseada no diálogo, no respeito e na diversidade, viabilizando que educandas e educandos tenham acesso a uma educação de qualidade, considerando aspectos objetivos e subjetivos que estão inseridos na ação de aprender e ensinar, e, isto irá colaborar para uma formação cidadã para homens e mulheres. Nossa formação enquanto pessoas cidadãs incluem as experiências que vivenciamos em diferentes espaços, inclusive dentro dos espaços escolares. A educação escolar, direito inalienável de qualquer cidadã ou cidadão, tem como objetivos, socializar o saber sistematizado, preparar educandos e educandas para o exercício da cidadania e qualificar para o trabalho.

Ainda vivenciamos um sistema educacional baseado no mérito e na difusão de um conhecimento muitas vezes descontextualizado e que não valoriza as diferentes formas de aprender e ensinar. Nossa prática educativa enfrenta limites, e "[...] a compreensão dos limites da prática educativa demanda indiscutivelmente a claridade política dos educadores com relação a seu projeto" (FREIRE, 2007 p. 48). A “[...] claridade política dos educadores" (FREIRE, 2007 p. 48), passa também pelo escurecimento de nossas práticas pedagógicas quando nos propomos a pensar e construir um projeto de educação plural, justo e democrático, pois, as histórias africanas e afro-brasileiras ainda são negadas, desvalorizadas e desqualificadas dentro do ambiente escolar.

Então, é importante que dialoguemos com grupos e coletivos negros, que tenhamos como bases autores e autoras que nos ajudem a construir conhecimentos a partir de outras perspectivas, neste caso, alicerçadas em conhecimentos de matrizes africanas.

Quando buscamos referências teóricas para as nossas pesquisas em pedagogia, nas raízes africanas, estamos pretendendo enegrecer os processos e pensamentos científicos e educacionais. Enegrecer significa a maneira própria de negros se porem ao mundo ao receberem o mundo em si. Enegrecer, face a face em que negro e branco se espelham, se comunicam sem deixar de ser o que cada um é. Assim sendo, o movimento negro brasileiro, ao propor o enegrecimento da sociedade, da educação, visa à construção de relações entre negros e não negros, entre diferentes grupos étnico-raciais, no sentido de que uns deixem de sentir-se superiores a outros, porque são incapazes de deslocar o olhar de seu próprio mundo, afim de compreender distintos modos de pensar, de ser, de viver (SILVA, 2005, p. 32). 
Por isso, caminhamos ao lado de homens e mulheres que historicamente vêm de maneiras e por experiências distintas, arando terras, abrindo caminhos para que a roda, a ginga, a brincadeira, o jogo, a dança, o tambor, a música, a poesia, o verso, os afetos, o convívio e a comensalidade sejam valorizados enquanto saberes que estruturam vidas, portanto devem ser reconhecidos, respeitados e praticados. Estes saberes podem, sem dúvidas, nos ajudar na prática de uma educação para e com a diversidade. Para combatermos o racismo precisamos nos transformar, transformar modos e espaços onde ele historicamente opera e se naturaliza, inclusive nos espaços escolares. Uma educação antirracista, engajada e comprometida pode promover esta mudança.

Em certo momento da pesquisa junto com as crianças na escola, recebemos Mestre Lumumba, tivemos a oportunidade de fazer uma roda de conversa além de cantarmos, tocarmos e dançarmos Jongo junto com ele. Durante a roda de conversa, Quero-quero pergunta “[...] porque os mestres são inteligentes e sabem tudo de nós?" (Dário de Campo, 09 nov. 2018), temos a resposta do Mestre Lumumba:

\begin{abstract}
Mestre Lumumba se sentou e as crianças fizeram muitas perguntas: você sabe Jongo? Você sabe fazer tambor? Como faz o tambor? Quem te ensinou a fazer tambor? Como você aprende um tanto de coisas? E as perguntas foram feitas tão rapidamente uma atrás da outra que o Mestre nem tinha tempo para responder. Vanessa pediu que esperassem um pouco para ele ir respondendo. Mestre Lumumba disse: mestre é o que aprende com as perguntas, todas essas perguntas de vocês estão me ensinando agora. Queroquero: mas como você aprende tanta coisa? Mestre: eu aprendo vivendo (Diário de Campo, 09 nov. 2018).
\end{abstract}

O tempo de viver é o tempo de aprender e ensinar. Nas culturas de matrizes africanas os aprendizados acontecem por meio do fazer. Em seus estudos sobre o candomblé, Souza Júnior (2002, p. 129) afirma: “[...] aprendem-se lições novas a cada instante e a cada pergunta, a dançar, a comer, a se comportar, a trocar bênção, axé e, sobretudo, a respeitar as tradições". Quando mestre Lumumba diz que aprende vivendo, ele nos conta que a própria vida é o lugar de construir e compartilhar experiências e saberes, são conhecimentos que fazem sentido e são vivenciados.

A partir da resposta do Mestre Lumumba, sobre "aprender vivendo" podemos caminhar em direção a algumas reflexões sobre os desafios da construção do esperançar no pesquisar Práticas Sociais e Processos Educativos, pensando sobre nossas experiências construídas no e com os Processos Educativos vivenciados em diferentes Práticas Sociais. O quê e como aprendemos com os grupos e comunidades com os quais dialogamos e compartilhamos pesquisa? Será que estamos aprendendo vivendo? E como é o nosso Tempo de aprender e ensinar? Parar, olhar, ouvir, pôr sentido. Dialogando com Paulo Freire e Mestre Lumumba as pistas nos levam a acreditar que ambos nos propõem ação, construção, concretização, poder de realização.

\title{
AlgunS APRENDIZAdOS E ENSINAMENTOS...
}

Esperançar histórias, escolas, pesquisas, jeitos de aprender e ensinar mais cheios de vida e de sentido requer o amor, aquele que o mesmo Freire nos fala: o amor armado, e Mestre Lumumba afirma: antagônico ao amor não é o ódio, mas o medo, o medo nos paralisa, nos impede e nos mata. Construir o esperançar em nossas pesquisas exige coragem. Coragem de nos colocarmos em diálogo e ação com grupos e comunidades que historicamente lutam para existirem, para sobreviverem às mazelas impostas por um estado que desumaniza e assimila. 
Deste modo, considerando que "[...] educar-se é participar ativamente do processo totalizante da cultura, através da qual o homem se faz e se refaz" (FIORI, 1986, p. 93), e que "[...] a cultura é a humanização do mundo, portanto humanização do homem" (FIORI, 1986, p. 85), um projeto de educação libertadora e humanizadora só poderá se concretizar quando considerarmos as múltiplas existências culturais e epistêmicas com as quais homens e mulheres se projetam no mundo. Reivindicamos a educação como encantamento, inventividade, e re-existência, e repudiamos a educação servil que aniquila, que mata, que impede, que controla.

Parafraseando Freire (2008), Oliveira (2007, p. 258) nos diz que: “[...] o encantamento é uma atitude de alteridade. Ninguém se encanta sozinho, ninguém encanta ninguém, encanta-se sempre em coletividade". Deste modo, a educação como encanto, como projeto de existência, só é possível se exercitada coletivamente, em grupos, comunidades, nas trocas e compartilhamentos de diferentes experiências. A educação que reivindicamos como encantamento, é uma educação que tem responsabilidade com a vida, com outro, com a alteridade, visto que o encantamento "[...] é uma atitude diante do mundo" (OLIVEIRA, 2006, p. 239).

As escolas, certamente com algumas exceções, como estão estruturadas hoje, não permitem, não viabilizam e não reconhecem o encantamento como potência educativa. A nossa crítica vai no sentido de afirmar que a escola ainda é hostil às gramáticas pelas quais os povos negros e indígenas afirmam suas existências. Estas gramáticas estão inscritas nos corpos que cantam, dançam, estão na comensalidade, no compartilhamento, nos tambores, nas brincadeiras, nas gingas.

Em nossas experiências mais distintas nos educamos e compartilhamos conhecimentos com diferentes pessoas. Muitas vezes, a escola alinhada sobre o trilho do conteúdo e de uma história unilateral não valoriza a diversidade de saberes. Entretanto, acreditamos que a escola é espaço de vida e potência, e por isso se configura como território importante para realização de intervenções que promovam mudanças e reorganizações. Sem dúvidas, a Lei 10.639/03 promoveu avanços para a constituição de práticas de ensino mais democráticas e plurais.

\section{VOU CAMINHAR QUE O MUNDO GIRA... ${ }^{6}$}

Apenas a existência da política pública e do marco legal não garante que as escolas, enquanto instituições formativas, tenham suas ações pedagógicas baseadas em múltiplas epistemologias. Para que isso ocorra, é preciso caminharmos lado a lado, de braços dados com a escola. As proposições devem vir acompanhadas de co-laborações. O caminho é longo e a caminhada se faz em seu tempo. Como nos ensina o provérbio africano: sozinha eu vou mais rápido, mas acompanhada, certamente vou mais longe. $\mathrm{E}$ como o mundo gira, acreditamos que em cada lugar, em cada comunidade, em cada escola os saberes vão se tecendo, se enredando em fortes e inspiradoras re-existências. Sabemos que apesar das mazelas e maldades, ainda existem homens, mulheres e crianças que cantam o ponto e encantam a vida, fazendo com que em cada esquina do mundo possamos partilhar saberes nas e com as rodas.

Assim, esperançamos pesquisando, agindo, dialogando desde a academia, de mãos dadas com as escolas, com as comunidades indígenas, com as comunidades quilombolas, com as jongueiras e jongueiros, com as comunidades congadeiras, com as crianças e com muitos outros. Hoje o desafio está maior, mais complexo, pois vivemos

\footnotetext{
${ }^{6}$ Ponto de Jongo cantado nas despedidas das rodas.
} 
um contexto político no qual as forças do projeto colonizador branco, heteronormativo, eurocentrado ganha força. Mas cheias de vida, amor armado, em busca do inédito viável e em comunhão, seguimos construindo caminhos dentro e fora das universidades, pois assim como nos ensina Freire (1996), a educação transforma as pessoas e estas transformam o mundo.

\section{REFERÊNCIAS}

ARAÚJO-OLIVERA, S. S. Exterioridade: o outro como critério. In: OLIVEIRA, M. W.; SOUSA, F. R. (org.). Processos educativos em práticas sociais: pesquisas em educação. São Carlos: EdUFSCar, 2014. p. 46-112.

BRASIL. Lei $\mathbf{n}^{\circ}$ 11.645, de 10 de março de 2008: altera a Lei $n^{\circ}$ 9.394, de 20 de dezembro de 1996, modificada pela Lei $\mathrm{n}^{\circ} 10.639$, de 9 de janeiro de 2003, que estabelece as diretrizes e bases da educação nacional, para incluir no currículo oficial da rede de ensino a obrigatoriedade da temática "História e Cultura Afro-Brasileira e Indígena”. Disponível em: http://www.planalto.gov.br/ccivil_03/_Ato20072010/2008/Lei/L11645.htm. Acesso em: 27 set. 2020.

BRASIL. Lei $\mathbf{n}^{\mathbf{0}}$ 10.639, de 09 de janeiro de 2003: altera a Lei ${ }^{\circ}$ 9.394, de 20 de dezembro de 1996, que estabelece as diretrizes e bases da educação nacional, para incluir no currículo oficial da Rede de Ensino a obrigatoriedade da temática "História e Cultura Afro-Brasileira". Disponível em: http://www.planalto.gov.br/ccivil_03/leis/2003/110.639.htm. Acesso em: 27 set. 2020.

BRASIL. Lei $n^{0}$ 9.394, de 20 de dezembro de 1996: estabelece as diretrizes e bases da educação nacional. Disponível em: http://www.planalto.gov.br/ccivil_03/leis/19394.htm. Acesso em: 30 ago. 2020.

DENZIN, A. S. Educação das relações étnico-raciais: processos educativos decorrentes de uma intervenção com africanidades. 2018. 377 p. Tese (Doutorado em Educação) - Centro de Educação e Ciências Humanas, Universidade Federal de São Carlos, São Carlos, 2018.

FIORI, E. M. Conscientização e educação. Educação e Realidade, v. 11, n. 1, p. 3-10, jan./jun. 1986.

FREIRE, P. Pedagogia da esperança: um reencontro com a pedagogia do oprimido. Rio de Janeiro: Paz e Terra, 2008.

FREIRE, P. Política e educação. São Paulo: Vila das Letras, 2007.

FREIRE, P. Pedagogia do oprimido. São Paulo: Paz e Terra, 1996.

OLIVEIRA, E. D. Filosofia da ancestralidade: corpo e mito na filosofia da educação brasileira. Curitiba: Editora Gráfica Popular, 2007.

OLIVEIRA, E. D. Cosmovisão africana no Brasil: elementos para uma filosofia afrodescendente. Curitiba: Editora Gráfica Popular, 2006.

SANTOS, B. S.; MENESES, M. P. Epistemologias do sul. São Paulo: Cortez, 2010.

SILVA, G. A. Jongo de Piquete: um novo olhar. Piquete: Ed. do Autor, 2007.

SILVA, P. B. G. Aprendizagem e ensino das africanidades brasileiras. In: MUNANGA, K. (org.). Superando o racismo na escola. Brasília: Ministério da Educação, Secretaria de Educação Continuada, Alfabetização e Diversidade, 2005. p. 155-172.

SILVA, V. P. Jongo na escola: contribuições para e na educação das relações étnico-raciais. 2020. 247 f. Tese (Doutorado em Educação) - Centro de Educação e Ciências Humanas, Universidade Federal de São Carlos, São Carlos, 2020.

SIMAS, L. A.; RUFINO, L. Fogo no mato: a ciência encantada das macumbas. Rio de Janeiro: Mórula, 
2018.

SOUZA JÚNIOR, V. C. As representações do corpo no universo afro-brasileiro. Projeto História: Revista do Programa de Estudos Pós-Graduados de História, v. 25, p. 125-144. 2002. Disponível em: https://revistas.pucsp.br/revph/article/view/10585. Acesso em: 29 out. 2020.

Recebido em: 30 out. 2020.

Aprovado em: $01 \mathrm{dez} .2020$. 